\title{
Evaluation of a chitosan-based edible film as carrier of natamycin to improve the storability of Saloio cheese
}

\author{
P. Fajardo ${ }^{\text {a }}$, J.T. Martins ${ }^{b}$, C. Fuciños ${ }^{c}$, L. Pastrana ${ }^{c}$, J.A. Teixeira ${ }^{b}$, A.A. Vicente ${ }^{b, *}$ \\ ${ }^{a}$ ANFACO-CECOPESCA, Colegio Universitario 16, 36310 Vigo (Pontevedra), Spain \\ ${ }^{\mathrm{b}}$ IBB - Institute for Biotechnology and Bioengineering, Centre of Biological Engineering, University of Minho, Campus de Gualtar, 4710-057 Braga, Portugal \\ ' Department of Analytical Chemistry and Food Science, University of Vigo, As Lagoas, 32004 Ourense, Spain
}

\section{A R T I C L E I N F O}

\section{Article history:}

Received 11 March 2010

Received in revised form 21 June 2010

Accepted 25 June 2010

Available online 14 July 2010

\section{Keywords:}

Chitosan

Edible coating

Natamycin

Shelf-life

Cheese

\begin{abstract}
A B S T R A C T
The purpose of this study was to evaluate the effects of the application of chitosan coating containing natamycin on the physicochemical and microbial properties of semi-hard cheese. Three cheese groups were prepared: samples without coating, samples coated with chitosan and with chitosan containing $0.50 \mathrm{mg} \mathrm{mL}^{-1}$ of natamycin, whose minimum inhibitory concentration was previously determinated on cheese surface. Microbiological analyses showed that natamycin coated samples presented a decrease on moulds/yeasts of $1.1 \log \left(\mathrm{CFU} \mathrm{g}^{-1}\right)$ compared to control after 27 days of storage. Addition of natamycin also affected $\mathrm{O}_{2}$ and $\mathrm{CO}_{2}$ permeability, increasing from 7.12 to $7.68 \times 10^{-15} \mathrm{~g}$. $(\mathrm{Pa} \mathrm{s} \mathrm{m})^{-1}$, and from 10.69 to $64.58 \times 10^{-14} \mathrm{~g}$.(Pa s m$)^{-1}$, respectively. The diffusion coefficient values of natamycin from the film to phosphate buffered saline solution and to the cheese were $3.60 \times 10^{-10}$ and $1.29 \times 10^{-12} \mathrm{~cm}^{2} \mathrm{~s}^{-1}$, respectively. This study demonstrated that chitosan-based coating/films can be used as release system containing natamycin to create an additional hurdle for moulds/yeasts in cheese thus contributing to extend its shelf-life.
\end{abstract}

(c) 2010 Elsevier Ltd. All rights reserved.

\section{Introduction}

Synthetic packaging films have led to serious ecological problems due to their non-biodegradability. The major concern of the consumer for environmental protection led food and packaging industries to increase research in biodegradable food packaging materials. In this context, biopolymers can be an alternative source for packaging materials development due to their biodegradability. Chitosan is one of a few natural cationic polysaccharides that can be derived from crustacean or fungi. Having antimicrobial properties against many bacteria, filamentous fungi and yeast (Rabea et al., 2003) chitosan application as edible film and coating is very attractive. The complex cheese composition along with environmental conditions during handling and storage often promote extensive mould and bacteria development at cheese surface, which considerably reduces its quality. Edible coatings can act as effective carriers of antimicrobials for treating cheese surfaces which are a likely location of microbial contamination. In addition, edible coatings can enhance food quality by acting as a semipermeable barrier to oxygen, carbon dioxide and water vapor exchange, leading to weight loss reduction and respiratory rate modification (Cerqueira et al., 2009a). Chitosan coatings were tested on different types of cheese aiming at prolonging their shelf life, such as

\footnotetext{
* Corresponding author. Tel.: +351253 604419; fax: +351253678986

E-mail address: avicente@deb.uminho.pt (A.A. Vicente).
}

Mozzarella (Altieri et al., 2005), Emmental (Coma et al., 2002), Regional Saloio (Cerqueira et al., 2009b), Apulia spreadable cheese (Gammariello et al., 2008); chitosan was used by itself, or as carrier of other natural antimicrobials, e.g. lysozyme (Duan et al., 2007), lysozyme and EDTA (Del Nobile et al., 2009).

Natamycin protects the surface of cheese against the development of mould (Reps et al., 2002; Var et al., 2006). However, the incorporation of antifungal agents onto food surface by spraying, dipping or coating without matrix may result in partial inactivation of the active substance (Reps et al., 2002) and a rapid diffusion within the bulk of food (Ouattara et al., 2000). The use of packaging films based on antimicrobial polymers could prove more efficient, by maintaining high concentrations of the active substance on food surface while preventing its migration, thereby maintaining a critical concentration for an extended period of time (Ouattara et al., 2000). Then, it is interesting to quantify the release of natamycin from the film. Several approaches are reported on drug release modeling (Crank, 1975; Flores et al., 2007; Peppas et al., 2000; Siepmann and Siepmann, 2008). The benefit of mathematical modeling consists in the possibility of predicting parameters of the release system aiming at providing information about the mechanisms that control drug release. Additionally, due to the low water solubility of natamycin their incorporation into a coating favors the good distribution in the cheese. In order to protect cheese surface from mould growth, natamycin is usually applied in a polyvinyl acetate base (Reps et al., 2002). However, other 
polymers have been tested as natamycin carriers such as, whey protein films (Pintado et al., 2010), cellulose polymer (De Oliveira et al., 2007; Dos Santos Pires et al., 2008) or casein (Yildirim et al., 2006). However, chitosan as carrier of natamycin has been used only in Hami melon (Cong et al., 2007). In the present work Saloio cheese was used to assay the effectiveness of a chitosan coating containing natamycin. This Portuguese cheese is a full fat cured regional cheese produced with a mixture of caprine, ovine and bovine pasteurized milk with a soft texture, a slightly acidulous flavor and it has a white pulp with some scattered eyeholes. Saloio cheese is submitted to a short ripening period at low temperatures and it is currently sold unpackaged or in a vacuum package (Pantaleão et al., 2007). Neither of these packaging systems is acceptable: the first system yields a cheese too hard, because of excessive water loss, while the second yields a white cheese with poor textural properties (Pantaleão et al., 2007). Moreover, one of the major problems related to this type of semi-hard cheese other than water loss is the occurrence of molds during cheese ripening and later on, throughout the distribution chain. The use of a chitosan coating containing natamycin is a way of extending the cheese's shelf-life.

The amount of the additive incorporated to food shall be limited to the lowest possible level necessary to accomplish the desired effect. In most works, the determination of natamycin's minimum inhibitory concentration (MIC) is performed absorbing natamycin on paper discs (Türe et al., 2008), or adding it into the film matrix (De Oliveira et al., 2007; Dos Santos Pires et al., 2008; Pintado et al., 2010). Later, MIC is calculated by direct measurement over agar plates spread with different indicator fungi. However, these methods present some problems: the antifungal properties of natamycin could be reduced due to the interaction with the coating film and also, agar has a high water content that could change the properties of the film; moreover, the release mechanism of active agents from film on cheese might differ.

To the best of our knowledge there has been no work reported neither on the use of a chitosan coating as a carrier of natamycin to retard mould growth on cheese surface nor on the direct use of cheese to calculate MIC of natamycin. Therefore, the purpose of this work was to evaluate the effectiveness of using a chitosan coating containing natamycin to prevent mould growth in Saloio cheese and to determine if natamycin would change the properties of the chitosan coating.

\section{Materials and methods}

\subsection{Raw materials}

The materials used to prepare the films and coatings were: chitosan with a degree of deacetylation of approximately $90 \%$ (Aqua Premier Co., Thailand); 87\% glycerol (Riedel de Häen, Germany); Tween 80 (Acros Organics, Belgium); lactic acid (Merck, Germany); and distilled water. A commercial semi-hard cheese, Regional Saloio (Portugal), was purchased from a local supermarket and stored in a refrigerator $\left(4^{\circ} \mathrm{C}\right)$ until use. The cheese's physicochemical composition is as follows: moisture, $46 \%$; fat, $25 \%$; protein, 18.4\%; total ash, 3.58\%; chlorides, $1.54 \%$; $\mathrm{pH} 4.8$; and total acidity, 1.40 (Pantaleão et al., 2007). PIRAMICIN, used as natamycin source contains 50\% lactose and 50\% natamycin and it was provided by VGP Pharmachem (Barcelona, Spain). In this work, unless otherwise indicated, natamycin is expressed as levels of impure natamycin (with 50\% lactose).

\subsection{Preparation of fungal cultures}

Aspergillus niger MUM 03.42, Penicillium crustosum MUM 02.30, P. commune MUM 9739 and P. roqueforti MUM 9838 were obtained from MUM (Micoteca da Universidade de Minho, Braga, Portugal). All fungi were grown on potato dextrose agar (PDA) (Difco laboratories, Detroit, MI, USA) and maintained on PDA slants at $4{ }^{\circ} \mathrm{C}$ for two months.

The inoculum was prepared by overlaying mature slants with sterile Tween $80,0.05 \%(\mathrm{w} / \mathrm{v})$, and gently scraping the surface with a Drigalski spatula. The mold culture suspensions were filtered through sterile cheesecloth to remove the mycelium and spore count was determined using a Neubauer chamber. Necessary dilutions were made with Tween $80,0.05 \%(\mathrm{w} / \mathrm{v})$, to obtain $10^{6}$ spores per mL counts.

\subsection{Coating and Films Preparation}

Coating solutions were prepared dissolving $0.5 \mathrm{~g}$ of chitosan in $90 \mathrm{~mL}$ of $1 \%(\mathrm{v} / \mathrm{v})$ lactic acid solution under agitation using a magnetic stirrer during $4 \mathrm{~h}$ at room temperature $\left(20^{\circ} \mathrm{C}\right)$. This suspension was then centrifuged $(5000 \times \mathrm{g}$ for $10 \mathrm{~min})$ to remove insoluble impurities and to avoid imperfections in the film. $0.2 \mathrm{~g}$ of Tween 80 as a surfactant and $0.5 \mathrm{~g}$ of glycerol as plasticizer were added and the volume was adjusted at $100 \mathrm{~mL}$ with $1 \%(\mathrm{v} / \mathrm{v}$ ) lactic acid solution. This coating formulation has been optimized for Regional Saloio cheese by Cerqueira et al. (2009b). To prepare the films, constant amounts ( $27.3 \mathrm{~g}$ and $12.8 \mathrm{~g}$ ) of the previous coating solution were cast onto $90 \mathrm{~mm}$ and $57 \mathrm{~mm}$ diameter Petri dishes, respectively, in order to maintain film thickness. The films were dried in an oven at $35{ }^{\circ} \mathrm{C}$ during $16 \mathrm{~h}$. The average thickness of films was measured randomly at eight points with a hand micrometer.

Natamycin containing films were prepared exactly as control films, but natamycin (powder) was added to films and mixed for about half hour with a magnetic stirrer just before spreading onto the Petri dishes.

\subsection{Minimum inhibitory concentration (MIC) of natamycin}

The cheese rind was removed at approximately $5 \mathrm{~mm}$ in depth, to eliminate the effect of some cracks already present on the cheese surface, and the cheeses were cut in small cylinders $(4 \mathrm{~cm}$ of diameter) and exposed to UV light for $10 \mathrm{~min}$. Coating solutions with different concentrations of natamycin $\left(0.0625-2 \mathrm{mg} \mathrm{mL}^{-1}\right)$ were prepared. Then pieces of cheese were coated with the solutions by gently spraying their surface until all of it was covered, being the residual coating allowed to drip off. Then, the cheeses were left overnight at $4{ }^{\circ} \mathrm{C}$ to allow them to dry. Later, the cheeses were inoculated with $10 \mu \mathrm{L}$ of a spore suspension at about $10^{6}$ spores per $\mathrm{mL}$ to simulate a contamination of the cheese during storage. The MIC was calculated for each strain individually. All cheeses were kept in a covered plastic box and incubated up to 7 days at $25^{\circ} \mathrm{C}$. MIC was recorded as the lowest concentration that resulted in no visible growth of fungi after 7 days of incubation.

Pieces of cheese coated with chitosan without natamycin and pieces which were not coated were used as control. The assays were performed in triplicate.

\subsection{Water vapor, oxygen and carbon dioxide permeability}

The measurements of water vapor $(W V P)$, Oxygen $\left(O_{2} P\right)$ and Carbon Dioxide $\left(\mathrm{CO}_{2} \mathrm{P}\right)$ permeability are described in Cerqueira et al. (2009b). WVP was determined gravimetrically on the basis of the ASTM E96-92 method. Shortly, film samples were placed on cups containing distilled water $(100 \% \mathrm{RH}$; $2337 \mathrm{~Pa}$ vapor pressure at $20^{\circ} \mathrm{C}$ ). The cups were placed on a desiccator (inside which fans were adapted to homogenize the atmosphere) and held at $0 \% \mathrm{RH}$ at $20^{\circ} \mathrm{C}$ using anhydrous silica gel. Weights were taken every $2 \mathrm{~h}$ to record moisture loss overtime. WVP was calculated 
by linear regression from the points of weight loss versus time, in the constant rate period.

$\mathrm{O}_{2} \mathrm{P}$ was determined according to the ASTM D 3985-02 (2002) method. Briefly, an oxygen permeation analyzer (Mettler-Toledo, Switzerland) was used to measure the oxygen transmission rate through films. $\mathrm{O}_{2} \mathrm{P}$ of the films was measured at $20 \pm 2{ }^{\circ} \mathrm{C}$ and $50 \pm 1 \%$ RH. $\mathrm{O}_{2} \mathrm{P}$ was calculated by multiplying oxygen transmission rate by the film thickness and dividing by the oxygen pressure difference (Cerqueira et al., 2009b).

$\mathrm{CO}_{2} \mathrm{P}$ was determined on the basis of the ASTM D 3985-02 (2002) method by gas chromatography (Chrompack 9001, Middelburg, Netherlands) with a column Porapak Q 80/100 mesh $2 \mathrm{~m} \times 1$ / $8 " \times 2 \mathrm{~mm}$ SS to separate the $\mathrm{CO}_{2}$ and with a column molecular sieve $5 \mathrm{~A} 80 / 100$ mesh $1 \mathrm{~m} \times 1 / 8^{\prime \prime} \times 2 \mathrm{~mm}$ to separate the $\mathrm{O}_{2}$ followed by thermal conductivity detector (TCD) at $110^{\circ} \mathrm{C}$. Helium at $23 \mathrm{~mL} \cdot \mathrm{min}^{-1}$ was used as carrier gas. A mixture containing $10 \%$ $\mathrm{CO}_{2}, 20 \% \mathrm{O}_{2}$, and $70 \% \mathrm{~N}_{2}$ was used as the standard for calibration.

All tests were conducted on the same sample three times and triplicate samples from three independent experiments were analyzed for each condition (films with and without natamycin).

\subsection{Opacity of the films}

The opacity of the films was determined according to the Hunter laboratory method, with a Minolta colorimeter (CR 300; Minolta, Japan), as the relationship between the opacity of each sample on the black standard $(\mathrm{Yb})$ and the opacity of each sample on the white standard (Yw) (Cerqueira et al. 2009b).

\subsection{Release of natamycin from films}

\subsubsection{To a liquid medium}

The diffusion cell consisted of a chamber to keep the temperature at $4{ }^{\circ} \mathrm{C}$ and a stainless steel net protecting the antimicrobial film from a magnetic bar used to stir the medium. Three films ( $8.5 \mathrm{~cm}$ diameter), weighing approximately $1.79 \mathrm{~g}$ and containing $21 \mathrm{mg}$ of pure natamycin, were cut in small pieces and immersed in $150 \mathrm{~mL}$ of phosphate buffered saline solution (PBS solution; $0.01 \mathrm{M}$ phosphate buffer, $2.7 \mathrm{mM}$ potassium chloride and $0.137 \mathrm{M}$ sodium chloride, $\mathrm{pH} 7.4$ ) at $4{ }^{\circ} \mathrm{C} .1 \mathrm{~mL}$ of PBS solution was taken out at selected times during $8 \mathrm{~h}$ to determine natamycin concentration in the solution; this was done spectrophotometrically at $319 \mathrm{~nm}$, in order to follow the release kinetics of the antifungal compound from the film. The solution of natamycin exhibits a very characteristic UV spectrum with three absorption maxima at 291, 305 and $319 \mathrm{~nm}$ (Capitán-Valley et al. 2000). The $319 \mathrm{~nm}$ wavelength was selected for natamycin absorbance measurements in order to avoid interferences with absorbance spectrum of chitosan.

\subsubsection{To the cheese}

Pieces of film $(1.5 \times 1.5 \mathrm{~cm})$ were put over slices of Saloio cheese $(0.5 \mathrm{~cm}$ of thickness). The amount of natamycin released to the cheese during a period of time was calculated by determining the amount left in the film covering the cheese. Then, to calculate the amount left in the film, at each sampling time a piece of film was taken out from the cheese and introduced in a glass tube containing $2 \mathrm{~mL}$ of PBS solution under shaking during $6 \mathrm{~h}$. These conditions were chosen taking into account the release kinetics of natamycin to PBS solution to make sure that the equilibrium was achieved and to keep an area-volume ratio equal to the one used in "in vitro" assays. After this incubation time the concentration of natamycin in PBS solution was measured at $319 \mathrm{~nm}$. Later, the natamycin fractional release $\left(N T_{R}\right)$ to the cheese was calculated by the following equation, as the difference between the total amount of natamycin initially charged in the film and the amount remaining in it at each sampling time:
$N T_{R}=1-\left(\frac{N T_{t=i}}{N T_{t=0}}\right)$

Where $N T_{t=i}$ is the concentration of natamycin in PBS solution at time $i, N T_{t=0}$ is the concentration of natamycin in PBS solution at time zero. The amount of natamycin released from the film to the cheese was calculated and plotted as a function of time $(t)$.

\subsubsection{Modeling}

A mathematical model for controlled release of natamycin from chitosan matrix was based on diffusion and on structural characteristics of the matrix polymer while also considering its swelling. It was assumed that (1) initially, natamycin concentration was homogeneously distributed in a thin sheet of film, (2) natamycin diffusion was considered to be unidirectional and perpendicular to the surface of the film. In the case of water diffusion in hydrophilic systems, two phenomena occur: a substantially stochastic phenomenon (related to Brownian motion), where the penetrant flows exclusively driven by a concentration gradient, and a relaxation phenomenon driven by the distance of the local system from the equilibrium (Buonocore et al., 2003). The model equation applied in our study is a combination of stochastic phenomena and polymer relaxation. Diffusion coefficients were determined from the data obtained using a relationship derived from the solution to Fick's Law for a plane sheet (Crank, 1975).

Based on other mass diffusion studies (Flores et al., 2007; Lao et al., 2009) diffusion parameters for the film at a fixed temperature and film composition of this work were calculated with the following equation:

$$
\begin{aligned}
M(t) & =M^{e q \cdot} \cdot\left\{X _ { F } \cdot \left\{1-\frac{8}{\pi^{2}} \cdot \sum_{n=0}^{n=\infty} \frac{1}{(2 \cdot n+1)^{2}}\right.\right. \\
& \left.\cdot \exp \left[-D \cdot(2 \cdot n+1)^{2} \cdot \pi^{2} \cdot \frac{t}{l^{2}}\right]\right\}+\left(1-X_{F}\right) \\
& \left.\cdot\left[1-\exp \left(-\frac{t}{\tau}\right)\right]\right\}
\end{aligned}
$$

where $M(t)$ is the total mass of natamycin released from the film at time $t ; M^{e q}$ is the amount of natamycin released at equilibrium as a consequence of stochastic phenomena and polymer relaxation; $X_{F}$ is a measure of the deviation of the transport mechanism from the ideal Fickian behavior. In fact, by definition $X_{F}$ ranges from 0 to 1 ; for $X_{F}$ equal to 1 the above equation is the solution of Fick's second law, whereas for $X_{F}$ equal to 0 , anomalous diffusion is obtained; $D$ is the diffusivity coefficient; $l$ is the film thickness; $t$ is the sampling time; $\tau$ is the relaxation time associated to polymer relaxation. The amount of the natamycin released from the film $\left(M(t) / M^{e q}\right)$ was calculated and plotted as a function of time $(t)$.

\subsection{Swelling of antifungal films}

Swelling kinetic was evaluated by immersing pre-weighed dry films $\left(w t_{i}\right)$ of $1 \times 1 \mathrm{~cm}$ into $25 \mathrm{~mL}$ of PBS solution at $4{ }^{\circ} \mathrm{C}$ under shaking. The weight gain of swollen films $\left(w t_{f}\right)$ was measured at selected times, after gently blotting the surface with Whatman paper, until equilibrium was reached. The average of four determinations is reported. The degree of swelling (\%Sw) was evaluated using the following equation (Mayachiew and Devahastin, 2010):

$\% \mathrm{Sw}=\left(\frac{w t_{f}-w t_{i}}{w t_{i}}\right) \times 100$

\subsection{Cheese coating}

Ninety pieces of cheese were randomly assigned to three treatments: (1) uncoated cheese, (2) coating with chitosan and 
(3) coating with chitosan containing $0.50 \mathrm{mg} \mathrm{mL}^{-1}$ of natamycin (MIC determined before). These cheese pieces, with approximately $15 \mathrm{~g}$, were coated by immersion (during $60 \mathrm{~s}$ ), the residual coating was allowed to drip off and cheeses were left for $2 \mathrm{~h}$ at $4{ }^{\circ} \mathrm{C}$ allowing the coating to dry (Yildirim et al., 2006). Later, in order to provide uniform coating, the bottom surface was dipped in the same way. All cheeses were left overnight at $4{ }^{\circ} \mathrm{C}$. Cheeses belonging to the same group were coated together using a stainless steel net. All cheeses were placed on plastic trays and then incubated up to 37 days at $4{ }^{\circ} \mathrm{C}$ and $85 \% \mathrm{RH}$ to reproduce as much as possible the typical shelf life storage conditions of cheese. Once the evaluation of the antimicrobial properties of natamycin was already performed during MIC assays, the option here was for not to inoculate the cheese surface, leaving the samples subjected to the occasional contamination from the surrounding atmosphere.

\subsection{Cheese analyses}

Cheese analyses were performed according to the directions given by Cerqueira et al. 2010 .

\subsubsection{Weight loss}

Weight loss of cheese was measured monitoring the weight changes every 2 days during 37 days, and calculated as percentage weight lost from the initial cheese weight.

\subsubsection{Moisture content}

The moisture content was determined by measuring weight loss at $105^{\circ} \mathrm{C}$ for $24 \mathrm{~h}$ until constant weight.

\subsubsection{Microbiological analyses}

Samples were analyzed for moulds and yeasts using potato dextrose agar (PDA, Difco ${ }^{\circledR}$ ) and psychrophilic and mesophilic bacteria using plate count agar (PCA, Difco ${ }^{\circledR}$ ). Each sample was diluted 1:10 in sterile distilled water and the mixture was homogenized for $1 \mathrm{~min}$ in a Stomacher 3500 (Seward Medical, UK.). After serial dilutions in PBS solution, aliquots of $1 \mathrm{~mL}$ were inoculated in PDA and PCA, and the plates were incubated at $25 \pm 2{ }^{\circ} \mathrm{C}$ for 7 days, $30 \pm 2{ }^{\circ} \mathrm{C}$ for $48 \mathrm{~h}$ and $4 \pm 2{ }^{\circ} \mathrm{C}$ for $7-10$ days to enumerate moulds and yeasts, mesophilic bacteria and psychrophilic bacteria, respectively.

\subsection{4. $\mathrm{pH}$ value}

The $\mathrm{pH}$ value was determined using a $\mathrm{pH}$ meter after the homogenization of the samples in the Stomacher.

Samples were analyzed at 0,12, 27 and 37 days of storage. At each sampling time five samples were analyzed per treatment.

\subsection{Statistical treatment}

Statistica software (Statistica for Windows, StatSoft, Tulsa, OK, USA) was used to fit Eq. (2) to the experimental data in order to determine natamycin diffusion parameters of the model. Comparisons between samples were analyzed using Student's $t$-test $(P<0.05$ and $P<0.1)$.

\section{Results and discussion}

\subsection{Minimum inhibitory concentration of natamycin}

The minimum inhibitory concentration observed after incubation at $25^{\circ} \mathrm{C}$ during 7 days was $0.50,0.50,0.25$ and $0.06 \mathrm{mg} \mathrm{mL}^{-1}$ for $A$. niger, $P$. crustosum, $P$. roquefortii and $P$. commune, respectively. $0.5 \mathrm{mg} \mathrm{mL}^{-1}$ was chosen as MIC for the subsequent experiments since this was the concentration that inhibited all strains assayed.

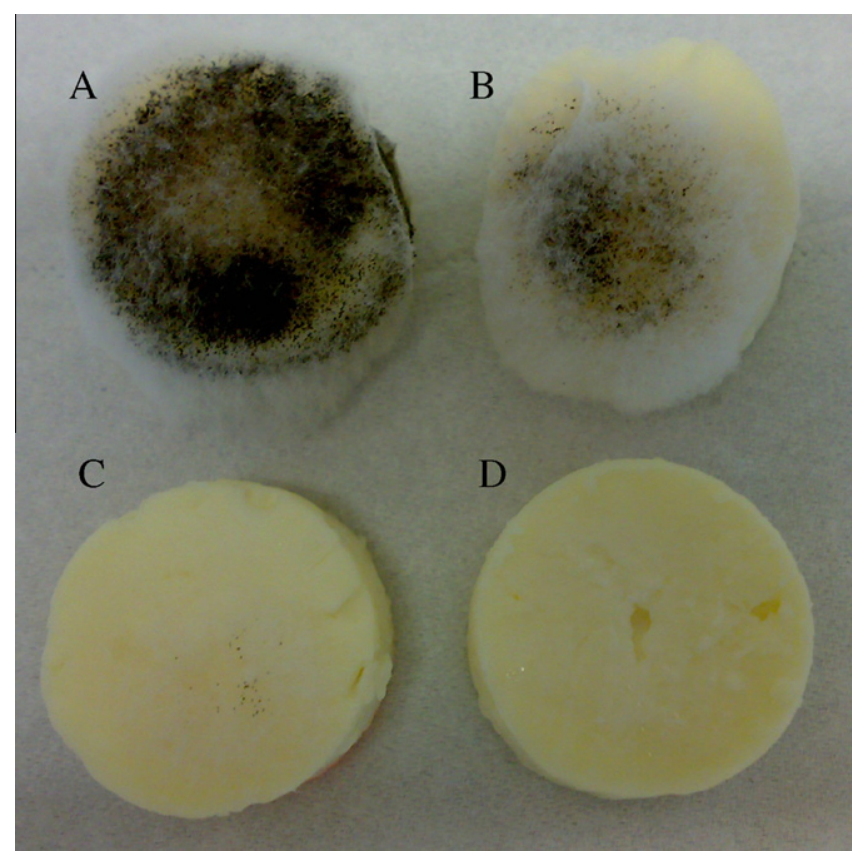

Fig. 1. Inhibition of $A$. niger growth with chitosan-natamycin coating after incubation at $25^{\circ} \mathrm{C}$ during 7 days. Uncoated cheese (a) and cheese coated with chitosan containing natamycin at $0.12 \mathrm{mg} \mathrm{mL}^{-1}$ (b), $0.25 \mathrm{mg} \mathrm{mL}^{-1}$ (C) and $0.50 \mathrm{mg} \mathrm{mL}^{-1}$ (D).

Fig. 1 shows growth inhibition of $A$. niger with chitosan-natamycin coating. The cheeses coated with chitosan $+0.5 \mathrm{mg} \mathrm{mL}^{-1}$ natamycin did not present contamination after inoculation with mould and stored at $25^{\circ} \mathrm{C}$ during one week, instead of uncoated cheeses which presented a noticeable contamination.

Türe et al. (2008) reported a MIC value for $A$. niger and $P$. roquefortii of $0.2 \mathrm{mg}$ and $0.1 \mathrm{mg}$ per g of solution, respectively, in methyl cellulose and wheat gluten films. These inhibitory concentrations are lower than those obtained in this work. However, Türe et al. (2008) used films with a thickness ranging between 0.23$0.69 \mathrm{~mm}$ to calculate the MIC by means of the agar disc diffusion assay. In our study antifungal activity was tested by directly coating the cheese with the solution containing $0.5 \mathrm{mg} \mathrm{mL}^{-1}$ natamycin, meaning that coating thickness and consequently the concentration of natamycin per square meter will be lower, possibly approaching values similar to those reported by Türe et al. (2008).

\subsection{Water vapor (WVP), $\mathrm{O}_{2}\left(\mathrm{O}_{2} \mathrm{P}\right)$ and $\mathrm{CO}_{2}\left(\mathrm{CO}_{2} \mathrm{P}\right)$ permeability}

The effect of adding natamycin to chitosan-based films on water vapor, $\mathrm{O}_{2}$ and $\mathrm{CO}_{2}$ permeability values was determined. In general, chitosan films have been reported to be good oxygen barriers but poor water barriers (Vargas et al., 2009). The addition of antimicrobials, such as natamycin, could modify these characteristics.

Table 1 shows the values of $W V P, O_{2} P$ and $\mathrm{CO}_{2} P$ obtained in this work for the tested films. These values were higher than those reported in Cerqueira et al. (2009b) for chitosan films, which is possibly due to the higher thickness of our films. The average thickness of control films ranged between 0.045 to $0.050 \mathrm{~mm}$ for the films cast on $90 \mathrm{~mm}$ and $57 \mathrm{~mm}$ diameter plates, respectively. Natamycin films containing $0.5 \mathrm{mg} \mathrm{mL}^{-1}$ of natamycin had average thickness values of $0.050-0.054 \mathrm{~mm}$. Since permeability is calculated by multiplying gas transmission rate by the film thickness and dividing by the pressure difference, the values of WVP and $\mathrm{O}_{2} \mathrm{P}$ obtained by Cerqueira et al. (2009b), 2.5 times lower 
Table 1

Values of water vapor, $\mathrm{O}_{2}$ and $\mathrm{CO}_{2}$ permeabilities and opacity of chitosan films and chitosan containing $0.5 \mathrm{mg} \mathrm{mL}^{-1}$ of natamycin.

\begin{tabular}{|c|c|c|c|c|c|}
\hline & $W V P \times 10^{-11}\left(\mathrm{~g} \cdot\left(\mathrm{m} \mathrm{s} \mathrm{Pa}^{-1}\right)\right.$ & $\mathrm{O}_{2} \mathrm{P} \times 10^{-15}\left(\mathrm{~g} \cdot(\mathrm{Pa} \mathrm{s} \mathrm{m})^{-1}\right)$ & $\mathrm{CO}_{2} \mathrm{P} \times 10^{-13}\left(\mathrm{~g} \cdot(\mathrm{Pa} \mathrm{s} \mathrm{m})^{-1}\right)$ & Opacity (\%) & Thickness (mm) \\
\hline Chitosan & $8.60 \pm 0.14^{a}$ & $7.12 \pm 0.23^{a}$ & $1.07 \pm 0.12^{\mathrm{a}}$ & $2.73 \pm 0.02^{b}$ & $0.045-0.050^{\mathrm{a}}$ \\
\hline Chitosan + Natamycin & $8.95 \pm 0.21^{a}$ & $7.68 \pm 0.10^{\mathrm{b}}$ & $6.46 \pm 0.55^{b}$ & $4.10 \pm 0.45^{a}$ & $0.050-0.054^{\mathrm{a}}$ \\
\hline
\end{tabular}

Values reported are the means \pm standard deviations $(n=3,95 \%$ confidence interval).

a-b Different letters in the same column indicate a statistically significant difference $(P<0.05)$

correspond to the fact that thickness of the films was also 2.5 times lower. Additionally, changes in film preparation methodology, film porosity and water content in the biopolymer could also justify the observed discrepancy.

The water vapor permeability of chitosan is attributed to its hydrophilic nature, which allows water molecules to interact with the matrix, thus increasing their rate of permeation. Natamycin incorporation into the chitosan matrix did not change WVP. Previous works on WVP of alginate-apple puree edible films containing essential oils also showed no significant differences when any of the essential oils was incorporated in the films (Rojas-Graü et al., 2007).

Films with a proper oxygen barrier can improve food quality and extend food shelf life. The value of $\mathrm{O}_{2} \mathrm{P}$ for chitosan films increased $(P<0.05)$ from $7.12 \times 10^{-15}$ to $7.68 \times 10^{-15} \mathrm{~g} \cdot(\mathrm{Pa} \mathrm{s} \mathrm{m})^{-1}$ due to the incorporation of natamycin. However, Bifani et al. (2007) obtained $\mathrm{O}_{2} \mathrm{P}$ values for carboxymethylcellulose films with murta leaves extract which were lower $\left(4.38 \times 10^{-10} \mathrm{~cm}^{3} \cdot(\mathrm{Pa} \mathrm{s} \mathrm{m})^{-1}\right)$ than those without the extract $\left(8.097 \times 10^{-10} \mathrm{~cm}^{3} \cdot(\mathrm{Pa} \mathrm{s} \mathrm{m})^{-1}\right)$. Natamycin may have created additional sites for the dissolution of oxygen, increasing mobility of $\mathrm{O}_{2}$ molecules within the polymer, and consequently $\mathrm{O}_{2} P$ values.

$\mathrm{CO}_{2}$ permeability increased $(P<0.05)$ from $1.07 \times 10^{-13}$ to $6.46 \times 10^{-13} \mathrm{~g} \cdot(\mathrm{Pa} \mathrm{s} \mathrm{m})^{-1}$ when natamycin was added to chitosan films. Martins et al. (2010) reported a similar behavior of $\mathrm{CO}_{2} \mathrm{P}$ for galactomannan-based edible films incorporating nisin. This selective action can be attributed to a better solubility of $\mathrm{CO}_{2}$ in the films with natamycin. The permeability of the $\mathrm{CO}_{2}$ is more sensible to changes in the film composition. Cerqueira et al. (2009b) observed that $\mathrm{CO}_{2} \mathrm{P}$ increased 7 times with the decrease of polysaccharide concentration in agar films of Gracilaria birdiae. Dos Santos Pires et al. (2008) found that films of cellulose show a heterogeneous structure due to the presence of natamycin larger size and bulky shape crystals, which can produce holes in the film. This could explain the higher $\mathrm{O}_{2}$ and $\mathrm{CO}_{2}$ permeability of films containing natamycin compared to chitosan films alone. Moreover, the addition of natamycin increased the opacity of the films, from $2.73 \%$ to $4.10 \%$.

\subsection{Release of natamycin from films}

A low diffusion coefficient is desirable in food applications to maintain a critical surface concentration of natamycin. In the literature, there are very few reports related to the use of natamycin in chitosan films. Before application on cheese, we studied natamycin diffusion from chitosan film to a liquid medium (PBS solution) aiming at determining the maximum release efficiency of the compound. The amount of natamycin released from the film matrix is illustrated in Fig. 2. The mathematical model (Eq. 2) programmed using Statistica software fitted experimental data, which indicates that the model adequately predicts the release of natamycin from the film. The results of fitting the experimental data to Eq. 2 are listed in Table 2.

The release results obtained for chitosan films in PBS solution showed a low value of $X_{F}$ (Table 2). This suggests that the release was mainly driven by polymer relaxation, i.e., the system was far from equilibrium at the moment that the film was put into contact

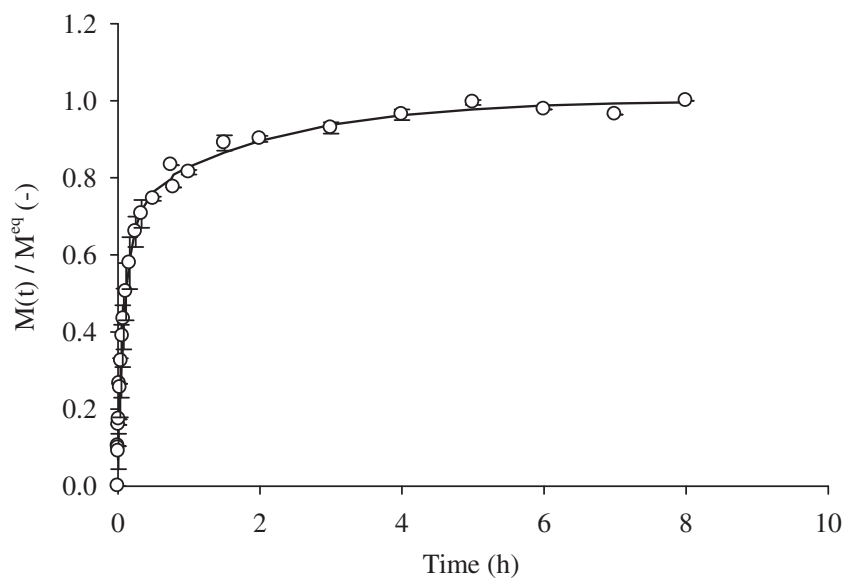

Fig. 2. Natamycin release kinetics from films of chitosan into PBS solution at $4{ }^{\circ} \mathrm{C}$. $\mathrm{Mt} / \mathrm{Meq}$ is expressed in $\mathrm{g}$ of natamycin released from the film at time $\mathrm{t} / \mathrm{g}$ of natamycin released at equilibrium. (O) Experimental data. The solid line represents the best fit of Eq. (2) to the experimental data.

Table 2

Model parameters obtained from fitting Eq. (2) to experimental natamycin release data, along with their standard deviations.

\begin{tabular}{lll}
\hline & PBS solution release & Cheese release \\
\hline$D\left(\mathrm{~cm}^{2} \mathrm{~s}^{-1}\right)$ & $3.60 \times 10^{-10} \pm 0.26 \times 10^{-10}$ & $1.29 \times 10^{-12} \pm 0.35 \times 10^{-12}$ \\
$X_{F}$ & $0.36 \pm 0.02$ & $0.79 \pm 0.06$ \\
$\tau(\mathrm{s})$ & $4.09 \times 10^{2} \pm 1.75 \times 10^{2}$ & $3.78 \times 10^{2} \pm 0.01 \times 10^{2}$ \\
\hline
\end{tabular}

$D$ : natamycin diffusion coefficient; $X_{F}$ : deviation of the transport mechanism from the ideal Fickian behavior; $\tau$ : relaxation time associated to polymer relaxation.

with PBS solution (Flores et al. 2007). This was consistent with a film that swells quickly and much more than the original dry size. Swelling kinetics showed a maximum degree of swelling equal to 1717\% after 2 min in PBS solution, calculated using Eq.3, and then a slow decrease to reach equilibrium (1015\%) at $45 \mathrm{~min}$. This similar profile has also been reported elsewhere for chitosan films (Azevedo et al., 2006; Baskar et al., 2009) and can be explained by residual lactic acid, surfactant or glycerol losses. The diffusion coefficient $(D)$ of natamycin within the film was $3.60 \times 10^{-10} \pm$ $0.26 \times 10^{-10} \mathrm{~cm}^{2} \mathrm{~s}^{-1}$ at $4{ }^{\circ} \mathrm{C}$, similar to the values obtained by Hanusová et al. (2010) with polyvinyldichloride lacquer coatings also used as natamycin carrier in cheese packaging, but at a different temperature $\left(23^{\circ} \mathrm{C}\right)$. To our knowledge, there is no information available in the literature on the diffusion coefficients of natamycin in other polymers.

As it was expected, high concentrations of natamycin were released to PBS solution. The direct contact with PBS solution was not going to provide sufficient insight into the release process of natamycin because of the very rapid diffusion kinetics of natamycin from the film under these circumstances. The diffusion process in solid food is indeed much more complex than in a simple liquid medium. As a consequence, it was decided to put the film into direct contact with a food matrix, in this case cheese, in order to have a more realistic evaluation of the diffusion process. Natamycin 


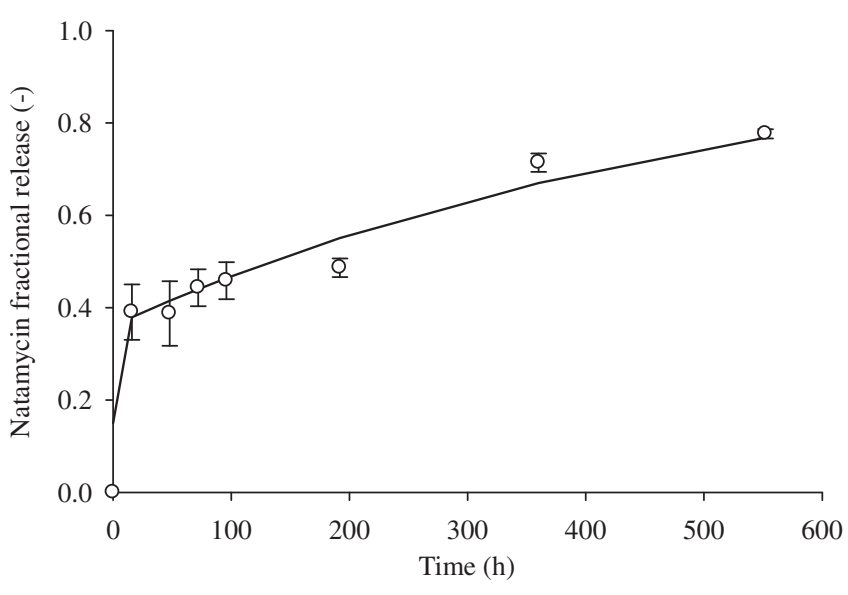

Fig. 3. Natamycin fractional release $\left(N T_{R}\right)$ from the film to the cheese calculated with Eq. (1) at $4{ }^{\circ} \mathrm{C}$. $N T_{R}$ is expressed in $\mathrm{g}$ of natamycin in PBS at time $i / g$ of natamycin released at time zero. (O) Experimental data. The solid line represents the best fit of Eq. (2) to the experimental data.

migration data from chitosan films to cheese samples exhibited a higher $X_{F}$ value. The main cause of this behavior is the abrupt decrease in water activity of the release medium, therefore a small amount of water diffused into the film, resulting in negligible swelling effects (Siepmann and Siepmann, 2008). Diffusion coefficient $\left(1.29 \times 10^{-12} \pm 0.35 \times 10^{-12} \mathrm{~cm}^{2} \mathrm{~s}^{-1}\right.$ at $\left.4^{\circ} \mathrm{C}\right)$ remained lower than that obtained in experiences performed in PBS solution, obviously caused by the lack of swelling effect in the release phenomenon. In fact, the equilibrium point of release was not reached after $552 \mathrm{~h}-23$ days - (Fig. 3), in contrast with the $6 \mathrm{~h}$ needed to reach the equilibrium when the release experiments were performed in PBS solution (Fig. 2). Despite of the slow release from chitosan films to the cheese samples, the values close to $80 \%$ of the initial natamycin loaded (Fig. 3) after 23 days demonstrate the potential efficiency of these films as active packaging material.

\subsection{Cheese analyses}

The lower weight loss of semi-hard cheeses coated with different materials (e.g. alginate, gellan, k-carrageenan, galactomannan) comparing with uncoated cheeses has been reported in the literature (Cerqueira et al., 2010; Kampf and Nussinovitch, 2000). To know if the addition of natamycin to chitosan could increase or decrease the positive effect of the chitosan coating, cheeses coated with chitosan alone and chitosan containing natamycin were weighed during the storage time ( 37 days) at $4{ }^{\circ} \mathrm{C}$ and the weight loss in both cases was measured and compared (Fig. 4). In both cases the weight loss increased linearly with time of storage. Although natamycin + chitosan coated cheeses presented a lower relative weight loss, this difference was only statistically significant $(P<0.05)$ during the first 12 days. After 37 days of storage the cheeses presented a $7 \%$ weight loss, similar to the losses reported by Pantaleão et al. (2007) in Saloio cheese using Humidipak packaging system.

Table 3 shows the microbiological results and values of $\mathrm{pH}$ and moisture of uncoated and coated cheeses. The $\mathrm{pH}$ of the samples was between 4.72 and 5.16. Only at the end of the assay the uncoated cheeses presented a significantly lower value of $\mathrm{pH}$ than coated cheeses. Del Nobile et al. (2009) also observed an increase in $\mathrm{pH}$ at end of storage period due to the mass exchange between the cheese and the coating.

The moisture of coated cheeses before storage was significantly higher than that of uncoated cheeses, essentially due to the water present in the coating itself. During storage at $4{ }^{\circ} \mathrm{C}$ this significant

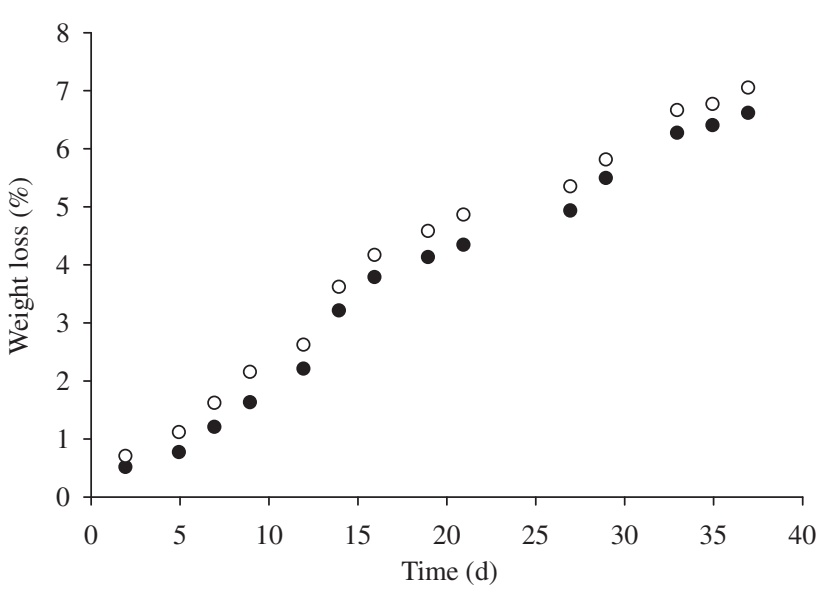

Fig. 4. Weight loss of cheeses during storage time. To facilitate reading, error bars are not shown. Cheeses samples coated with chitosan (O) or with chitosan containing $0.50 \mathrm{mg} \mathrm{mL}^{-1}$ of natamycin $(\bullet)$.

difference was only kept for natamycin + chitosan coated cheeses. This is in agreement with weight loss values, since during the first weeks cheeses with natamycin + chitosan coating lost less weight than chitosan coated cheeses. At the end of the storage period no differences $(P<0.05)$ in moisture content were observed.

Microbiological analyses are shown in Table 3. It is stated that psychrophilic microorganisms cause important economical losses as a result of lipolytic and proteolytic activities and may be present at a level of $10^{6} \mathrm{CFU} \mathrm{g}^{-1}$ in milk and milk products (Var et al. 2006). In our study psycrophilic bacteria counts were lower than $100 \mathrm{CFU} \mathrm{g}^{-1}$ in the first 12 days of storage. Therefore, it was decided to analyze only mesophilic bacteria in the subsequent sampling times since these bacteria could be used as an indicator of contamination during production and ripening of cheese. Microbiological analyses showed no statistically significant differences between cheese samples at $P<0.05$; however, differences become statistically significant at $P<0.1$ (Table 3 ). The counts obtained for mesophilic and mould/yeast ranged between 6.29-7.51 and 4.53$6.06 \log \left(\mathrm{CFU} \mathrm{g}^{-1}\right)$, respectively. At 27 days of storage natamycin + chitosan coated cheeses presented lower mould/yeast $(4.95 \pm 0.27)$ and mesophilic bacteria $(6.83 \pm 0.53)$ counts when compared to the uncoated samples $(6.06 \pm 1.25, P=0.087$, for yeast/mould and $7.51 \pm 0.51, P=0.073$, for mesophilic bacteria). It is important to note that the results on this table were obtained under no inoculation conditions. This means that large differences were not to be expected once the counts reported in Table 3 were performed in the whole cheese samples and not only at their surface. The minimum shelf life for Saloio cheese is 50 days, but after 37 days the uncoated cheeses began to show fungal growth at the surface and this time was taken as the end of cheese analysis to avoid contamination of the refrigeration room. Then, 37 days was reported as the last sampling time. Cerqueira et al. (2010) found statistically lower counts $(P<0.05)$ for total mould/yeast and mesophilic bacteria counts in Saloio cheese coated with galactomannan when compared to the uncoated cheeses, stored at $20^{\circ} \mathrm{C}$, but these differences disappeared when the samples were stored at $4{ }^{\circ} \mathrm{C}$. These results are in agreement with those observed in this work, where the effectiveness of the chitosan-natamycin coating was demonstrated when the cheeses were inoculated with moulds and stored at $25^{\circ} \mathrm{C}$, temperature at which the microorganisms grow faster. However, no significant differences $(P<0.05)$ were found in microbiological counts between coated and uncoated cheeses without inoculation at refrigerated temperatures. It is expected that the protective effect of natamycin coating will be more evident if the temperature of storage exceeds the 
Table 3

Total moulds/yeast, psychrophilic and mesophilic bacteria counts $\log \left(\mathrm{CFU} \mathrm{g}{ }^{-1}\right)$, values of $\mathrm{pH}$ and moisture of cheese samples during storage at $4{ }^{\circ} \mathrm{C}$.

\begin{tabular}{|c|c|c|c|c|}
\hline & \multicolumn{4}{|l|}{ Time } \\
\hline & 0 day & 12 days & 27 days & 37 days \\
\hline \multicolumn{5}{|l|}{ Moulds/yeast } \\
\hline Uncoated & $5.52 \pm 0.35^{\mathrm{a}}$ & $5.99 \pm 1.15^{\mathrm{a}}$ & $6.06 \pm 1.25^{\mathrm{a}}$ & $5.04 \pm 1.25^{\mathrm{a}}$ \\
\hline Chitosan & $5.60 \pm 0.18^{a}$ & $5.95 \pm 0.52^{\mathrm{a}}$ & $5.74 \pm 1.49^{\mathrm{ab}}$ & $4.53 \pm 1.18^{\mathrm{a}}$ \\
\hline \multirow[t]{2}{*}{ Chitosan + Natamycin } & $5.74 \pm 0.20^{\mathrm{a}}$ & $5.55 \pm 0.97^{a}$ & $4.95 \pm 0.27^{b}$ & $4.89 \pm 1.21^{\mathrm{a}}$ \\
\hline & Psychrophiles & Psychrophiles & Mesophiles & Mesophiles \\
\hline Uncoated & $<2.00$ & $<2.00$ & $7.51 \pm 0.51^{\mathrm{a}}$ & $6.29 \pm 0.89^{\mathrm{ab}}$ \\
\hline Chitosan & $<2.00$ & $<2.00$ & $7.12 \pm 0.55^{\mathrm{ab}}$ & $6.56 \pm 0.23^{b}$ \\
\hline Natamycin & $<2.00$ & $<2.00$ & $6.83 \pm 0.53^{\mathrm{b}}$ & $7.03 \pm 0.37^{\mathrm{a}}$ \\
\hline \multicolumn{5}{|l|}{$\mathrm{pH}$} \\
\hline Uncoated & $4.80 \pm 0.11^{\mathrm{a}}$ & $5.03 \pm 0.10^{a}$ & $5.08 \pm 0.06^{\mathrm{a}}$ & $5.02 \pm 0.03^{\mathrm{a}}$ \\
\hline Chitosan & $4.72 \pm 0.16^{\mathrm{a}}$ & $5.01 \pm 0.05^{\mathrm{a}}$ & $4.99 \pm 0.07^{\mathrm{a}}$ & $5.12 \pm 0.07^{\mathrm{b}}$ \\
\hline Chitosan + Natamycin & $4.75 \pm 0.09^{\mathrm{a}}$ & $5.02 \pm 0.09^{a}$ & $5.00 \pm 0.08^{a}$ & $5.16 \pm 0.02^{\mathrm{b}}$ \\
\hline \multicolumn{5}{|l|}{ Moisture (\%) } \\
\hline Uncoated & $47.03 \pm 2.50^{\mathrm{a}}$ & $45.35 \pm 3.41^{\mathrm{a}}$ & $44.27 \pm 2.77^{\mathrm{a}}$ & $44.74 \pm 3.24^{\mathrm{a}}$ \\
\hline Chitosan & $50.80 \pm 2.33^{\mathrm{b}}$ & $47.35 \pm 1.26^{\mathrm{ab}}$ & $46.45 \pm 1.96^{\mathrm{ab}}$ & $46.71 \pm 2.21^{\mathrm{a}}$ \\
\hline Chitosan + Natamycin & $51.05 \pm 2.16^{\mathrm{b}}$ & $49.42 \pm 1.86^{\mathrm{b}}$ & $47.57 \pm 2.60^{\mathrm{b}}$ & $46.81 \pm 1.84^{\mathrm{a}}$ \\
\hline
\end{tabular}

Values reported are the means \pm standard deviation $(n=5)$.

a-b Different letters in the same column indicate a statistically significant difference $(P<0.05$ for $\mathrm{pH}$ and moisture and $P<0.1$ for bacteria and mould/ yeast counts)

refrigeration temperature, e.g. when a break in the cold chain happens, or if a contamination during storage occurs.

\section{Conclusion}

Based in the minimum inhibitory concentration obtained, chitosan coatings containing $0.50 \mathrm{mg} \mathrm{mL}^{-1}$ of natamycin were applied on cheese samples and their shelf-life was evaluated. Natamycin caused an increase of $\mathrm{O}_{2} \mathrm{P}$ and $\mathrm{CO}_{2} \mathrm{P}$ but did not alter $W V P$. This type of cheese is sold unpackaged, so its shelf-life is reduced. Although natamycin has been used for many years, the incorporation of natamycin on chitosan-based films could act as an additional post-processing safety measure, once the inhibitory effect on microbial growth of both components (natamycin and chitosan) is expected to provide protection against a broad spectrum of microorganisms. The controlled release of natamycin from chitosan film would address the limitation of rapid loss of natamycin applied directly on cheese surface. Therefore, the present work points at new alternative to synthetic films for the cheese industry, demonstrating the ability of chitosan films to be a carrier of natamycin.

\section{Acknowledgements}

Paula Fajardo was funded by a postdoctoral fellowship from the Plan Galego de Investigación, Desenvolvemento e Innovación Tecnolóxica-Incite (2006-2010) (Xunta de Galicia). Joana T. Martins gratefully acknowledges the Fundação para a Ciência e Tecnologia (FCT, Portugal) for her fellowship (SFRH/BD/32566/2006).

\section{References}

Altieri, C., Scrocco, C., Sinigaglia, M., Del Nobile, M.A., 2005. Use of chitosan to prolong mozzarella cheese shelf life. Journal of Dairy Science 88 (8), 2683-2688.

Azevedo, E.P., Saldanha, T.D.P., Navarro, M.V.M., Medeiros, A.C., Ginani, M.F., Raffin, F.N., 2006. Mechanical properties and release studies of chitosan films impregnated with silver sulfadiazine. Journal of Applied Polymer Science 102 (4), 3462-3470.

Baskar, D., Sampath Kumar, T.S., 2009. Effect of deacetylation time on the preparation, properties and swelling behavior of chitosan films. Carbohydrate polymers $78(4), 767-772$.

Bifani, V., Ramírez, C., Ihl, M., Rubilar, M., García, A., Zaritzky, N., 2007. Effects of murta (Ugni molinae Turcz) extract on gas and water vapor permeability of carboxymethylcellulose-based edible films. LWT - Food Science and Technology 40 (8), 1473-1481.
Buonocore, G.G., Del Nobile, M.A., Panizza, A., Bove, S., Battaglia, G., Nicolais, L., 2003. Modeling the lysozyme release kinetics from antimicrobial films intended for food packaging applications. Journal of Food Science 68 (4), 1365-1370.

Capitán-Valley, L.F., Checa-Moreno, R., Navas, N., 2000. Rapid ultraviolet spectrophotometric and liquid chromatographic methods for the determination of natamycin in lactoserum matrix. Journal of AOAC International 83 (4), 802-808.

Cerqueira, M.A., Lima, A.M., Teixeira, J.A., Moreira, R.A., Vicente, A.A., 2009a Suitability of novel galactomannans as edible coatings for tropical fruits. Journal of Food Engineering 94 (3-4), 372-378.

Cerqueira, M.A., Lima, A.M., Souza, B.W.S., Teixeira, J.A., Moreira, R.A., Vicente, A.A., 2009b. Functional polysaccharides as edible coatings for cheese. Journal of Agricultural and Food Chemistry 57 (4), 1456-1462.

Cerqueira, M.A., Sousa-Gallagher, M.J., Macedo, I., Rodriguez-Aguilera, R., Souza, B.W.S., Teixeira, J.A., Vicente, A.A., 2010. Use of galactomannan edible coating application and storage temperature for prolonging shelf-life of "Regional" cheese. Journal of Food Engineering 97 (1), 87-94.

Coma, V., Martial-Gros, A., Garreau, S., Copinet, A., Salin, F., Deschamps, A., 2002. Edible antimicrobial films based on chitosan matriz. Journal of Food Science 67 (3), 1162-1169.

Cong, F., Zhang, Y., Dong, W., 2007. Use of surface coatings with natamycin to improve the storability of Hami melon at ambient temperature Postharvest. Biology and Technology 46 (1), 71-75.

Crank, J., 1975. The mathematics of diffusion, second ed. Oxford University Press Inc., New York.

De Oliveira, T.M., De Fátima Ferreira Soares, N , Pereira, R.M., Fraga, K., 2007. Development and evaluation of antimicrobial natamycin-incorporated film in gorgonzola cheese conservation. Packaging Technology and Science 20 (2), 147153.

Del Nobile, M.T., Gammariello, D., Conte, A., Attanasio, M., 2009. A combination of chitosan, coating and modified atmosphere packaging for prolonging Fior di latte cheese shelf life. Carbohydrate Polymers 78 (1), 151-156.

Dos Santos Pires, A.C., De Fátima Ferreira Soares., N., De Andrade, N.J., Da Silva, L.H.M., Camilloto, G.P., Bernardes, P.C., 2008. Development and evaluation of active packaging for sliced mozzarella preservation. Packaging Technology and Science 21 (7), 375-383.

Duan, J., Park, S.I., Daeschel, M.A., Zhao, Y., 2007. Antimicrobial chitosan-lysozyme (CL) films and coatings for enhancing microbial safety of mozzarella cheese. Journal of Food Science 72 (9), M355-M362.

Flores, S., Conte, A., Campos, C., Gerschenson, L., Del Nobile, M., 2007. Mass transport properties of tapioca-based active edible films. Journal of Food Engineering 81 (3), 580-586.

Gammariello, D., Chillo, S., Mastromatteo, M., Di Giulio, S., Attanasio, M., Del Nobile, M.A., 2008. Effect of chitosan on the rheological and sensorial characteristics of apulia spreadable cheese. Journal of Dairy Science 91 (11), 4155-4163.

Hanusová, K., Stastná, M., Votavová, L., Klaudisová, K., Dobiás, J., Voldrich, M., Marek, M., 2010. Polymer films releasing nisin and/or natamycin from polyvinyldichloride lacquer coating: nisin and natamycin migration, efficiency in cheese packaging. Journal of Food Engineering. doi: 10.1016/j.jfoodeng.2010.01.034.

Kampf, N., Nussinovitch, A., 2000. Hydrocolloid coating of cheeses. Food Hydrocolloids 14 (6), 531-537.

Lao, L.L., Venkatraman, S.S., Peppas, N.A., 2009. A novel model and experimental analysis of hydrophilic and hydrophobic agent release from biodegradable polymers. Journal of Biomedical Materials Research - Part A 90 (4), 1054-1065.

Martins, J.T., Cerqueira, M.A., Souza, B.W.S., Avides, M.C., Vicente, A.A., 2010. Shelf life extension of ricotta cheese using coatings of galactomannans from 
nonconventional sources incorporating nisin against Listeria monocytogenes. Journal of Agricultural and Food Chemistry 58 (3), 1884-1891.

Mayachiew, P., Devahastin, S., 2010. Effects of drying methods and conditions on release characteristics of edible chitosan films enriched with Indian gooseberry extract. Food Chemistry 118 (3), 594-601.

Ouattara, B., Simard, R.E., Piett, G., Bégin, A., Holley, R.A., 2000. Inhibition of surface spoilage bacteria in processed meats by application of antimicrobial films prepared with chitosan. International Journal of Food Microbiology 62 (1-2), 139-148.

Pantaleão, I., Pintado, M.M.E., Poças, M.F.F., 2007. Evaluation of two packaging systems for regional cheese. Food Chemistry 102 (2), 481-487.

Peppas, N.A., Bures, P., Leobandung, W., Ichikawa, H., 2000. Hydrogels in pharmaceutical formulations. European Journal of Pharmaceutics and Biopharmaceutics 50 (1), 27-46.

Pintado, C.M.B.S., Ferreira, M.A.S.S., Sousa, I., 2010. Control of pathogenic and spoilage microorganisms from cheese surface by whey protein films containing malic acid. Nisin and natamycin. Food Control 21 (3), 240-246.

Rabea, E.I., Badawy, M.E.T., Stevens, C.V., Smagghe, G., Steurbaut, W., 2003. Chitosan as antimicrobial agent: applications and mode of action. Biomacromolecules 4 (6), 1457-1465.
Reps, A., Drychowski, L.J., Tomasik, J., Winiewska, K., 2002. Natamycin in ripening cheeses. Pakistan Journal of Nutrition 1 (5), 243-247.

Rojas-Graü, M.A., Avena-Bustillos, R.J., Olsen, C., Friedman, M., Henika, P.R., MartínBelloso, O., Pan, Z., McHugh, T.H., 2007. Effects of plant essential oils and oil compounds on mechanical, barrier and antimicrobial properties of alginateapple puree edible films. Journal of Food Engineering 81 (3), 634-641.

Siepmann, J., Siepmann, F., 2008. Mathematical modeling of drug delivery. International Journal of Pharmaceutics 364 (2), 328-343.

Türe, H., Eroglu, E., Soyer, F., Özen, B., 2008. Antifungal activity of biopolymers containing natamycin and rosemary extract against Aspergillus niger and Penicillium roquefortii. International Journal of Food Science and Technology 43 (11), 2026-2032.

Var, I., Erginkaya, Z., Güven, M., Kabak, B., 2006. Effects of antifungal agent and packaging material on microflora of Kashar cheese during storage period. Food Control 17 (2), 132-136.

Vargas, M., Albors, A., Chiralt, A., González-Martínez, C., 2009. Characterization of chitosan-oleic acid composite films. Food Hydrocolloids 23 (2), 536-547.

Yildirim, M., Güleç, F., Bayram, M., Yildirim, Z., 2006. Properties of Kashar cheese coated with casein as a carrier of natamycinItalian. Journal of Food Science 18 (2), 127-138. 